\title{
Should Years of Schooling Be Used to Guide Treatment of Coronary Risk Factors?
}

\author{
Kevin Fiscella, MD, MPH \\ Peter Franks, $M D^{2}$ \\ ${ }^{1}$ Departments of Family Medicine, and \\ Community and Preventive Medicine, \\ University of Rochester School of Medicine, \\ Rochester, NY \\ ${ }^{2}$ Department of Family and Community \\ Medicine, University of California School \\ of Medicine, Davis, Davis, Calif
}

\begin{abstract}
PURPOSE We wanted to compare the risk of death from coronary heart disease (CHD) for patients of low socioeconomic status, measured by educational level, with established risk factors.

METHODS We undertook a prospective cohort study. Participants included a representative sample of 6,479 adults aged 25 to 74 years in the United States who were free of CHD at enrollment in the first National Health and Nutrition Examination Survey (NHANES I).
\end{abstract}

RESULTS Baseline measures included years of education, age, sex, systolic blood pressure, diabetes, total cholesterol level, and smoking. Outcome was death within 10 years from CHD. The relative risk (RR) associated with less than 12 years of education compared with more than 12 years (RR $1.5 ; 95 \%$ confidence interval [Cl], 1.2-1.8) was comparable to being male (RR 1.4; $95 \% \mathrm{Cl}, 1.2-1.6)$, smoking (RR 1.4; 95\% Cl, 1.1-1.6), having a total cholesterol level of greater than $280 \mathrm{mg} / \mathrm{dL}$ (RR $1.6 ; 95 \% \mathrm{Cl}, 0.9-2.7$ ), and systolic blood pressure of 130 $139 \mathrm{~mm} \mathrm{Hg}$ (RR 1.6; $95 \% \mathrm{Cl}, 1.0-2.4)$. Findings were comparable for estimates of absolute risk.

CONCLUSIONS Low educational level is associated with comparable risk as established risk factors for CHD mortality. Incorporation of educational level into riskbased guidelines for treatment could potentially reduce socioeconomic disparities in CHD by lowering thresholds for treatment.

Ann Fam Med 2004;2:469-473. DOI: 10.1370/afm.88.

\section{INTRODUCTION}

T The relationship between lower socioeconomic status measured by education, income, or occupation and mortality is well established. ${ }^{1-4}$ Socioeconomic disparities in morbidity and mortality from coronary heart disease (CHD) represent a major cause of socioeconomic disparities in overall mortality in the United States. ${ }^{5.8}$

Evidence suggests that the relationship between lower socioeconomic status and CHD is, in part, independent of traditional CHD risk factors, including hypertension, elevated cholesterol levels, diabetes mellitus, and smoking. ${ }^{9-12}$ Despite these findings, risk-based treatment guidelines, such as the Adult Treatment Panel III (ATP III) from the National Cholesterol Education Program, ${ }^{10}$ do not account for the effects of socioeconomic status on overall risk of death from CHD. Yet, if lower socioeconomic status independently predicts CHD risk, then it could be used to identify persons in need of earlier or more intensive management of modifiable risk factors, such as elevated low-density lipoprotein (LDL) levels.

In this study, we compare the independent risk associated with low educational level with traditional CHD risk factors. Specifically, we use nationally representative data from the United States to compare the rates of $\mathrm{CHD}$ death within 10 years based upon these factors. 


\section{METHODS}

\section{Population}

The first National Health and Nutrition Examination Survey (NHANES I), conducted between 1971 and 1975, collected sociodemographic, medical history, and clinical and laboratory information from several national probability samples of the civilian noninstitutionalized US population. ${ }^{13,14}$ The NHANES I Epidemiologic Follow-up Study (NHEFS) was designed to trace and reinterview respondents aged 25 to 74 years. ${ }^{15,16}$ Active follow-up surveys in NHEFS were conducted in 1982 to $1984,1986,1987$, and 1993. Data were collected from interview surveys, medical records from health care facilities, and death certificates for all decedents. The class-specific mortality of the NHEFS cohort based on age, race, and sex is similar to that experienced by the US population. ${ }^{17}$ Compared with persons with vital statistics follow-up information, those lost to follow-up were younger, had lower blood pressure and cholesterol levels, and were more likely to be smokers. Persons with baseline CHD $(n=56)$ were excluded from these analyses.

\section{Measures}

The following predictors were included in the models: age (categorized as <35, 35-44, 45-54,55-64, and 65-

74 years), sex, baseline systolic blood pressure (categorized as <120,120-129,130-139, 140-159, and $160 \mathrm{~mm}$ $\mathrm{Hg}$ or greater), baseline total cholesterol level (categorized as <200, 200-239, 240-279, and $280 \mathrm{mg} / \mathrm{dL}$ or greater), presence at baseline of diabetes mellitus, baseline smoking status (smoker or not), and baseline educational status (categorized as $<12$ years, 12 years, or $>12$ years of school). Outcome was death from CHD or not, at 10 years' follow-up, based on death certificate (ICD-9 codes 410-414).

\section{Statistical Analysis}

The NHANES I survey used multistage stratified probability samples of clusters of persons. Persons living in poverty areas, women of childbearing age, and elderly persons were oversampled. To accommodate the complex survey design, the statistical package SUDAAN was used to conduct the statistical analyses. ${ }^{18}$ SUDAAN uses a Taylor series approximation method to compute variances that allow adjustment for the multistage cluster-sampling strategy. Weights provided on the public-use tapes were used to adjust for survey oversampling and nonresponse to yield population estimates of all parameter estimates. We used logistic regression models to determine the 10 year risk for mortality from CHD associated with baseline age, education, sex, blood pressure, diabetes, cholesterol level and smoking. Odds ratios were converted to relative risk ratios. ${ }^{19} \mathrm{~A}$ Cox proportional hazards survival analysis yielded results similar to those reported here, but the logistic regression analyses are reported because they allow calculation of adjusted predicted marginal risk for each factor. Predictive margins provide an estimate of absolute risk associated with that variable taking into account the covariate distribution of the sample. ${ }^{20}$

\section{RESULTS}

Ascertainment of risk factors and 10 -year status was available for 6,637 persons (96\%). The prevalence of the risk factors 
by education is shown in Table 1 . In a multivariate analysis, significant predictors of CHD mortality in order of relative risk were older age, systolic blood pressure, diabetes, cholesterol level, having less than 12 years of education, being male, and smoking (Table 2). The addition of race to the models had little effect on the relative risks for any of the risk factors (results not shown). There were no statistically significant interactions among the key variables and no problems with collinearity.

The predicted marginal risk of CHD associated with these risk factors is also displayed in Table 2. Compared with persons having more than 12 years of education, persons with less than 12 years of education had a $2.4 \%(95 \% \mathrm{CI}$, 1.2-3.6) greater absolute risk of 10-year CHD mortality. This effect is comparable to being male compared with being female $(2.3 \% ; 95$ $\% \mathrm{CI}, 1.2-3.4)$, and age 65 years and older compared with 35 to 44 years $(2.8 \% ; 95 \% \mathrm{CI}, 1.6-3.9)$. The inclusion of persons with CHD in the analysis did not appreciably alter the results (results not shown).

Analyses stratified by educational level are shown in Table 3 . At each level of cholesterol, the adjusted marginal predicted risk of CHD mortality is greater for persons with fewer than 12 years of education than for persons with more than 12 years. Based on these adjusted predictive margins, and assuming $100 \%$ effectiveness of cholesterol-reducing medication, the numbers needed to treat to reduce the mortality risk for those with a cholesterol level of greater than 280 $\mathrm{mg} / \mathrm{dL}$ to that of persons with a cholesterol level of less than $200 \mathrm{mg} / \mathrm{dL}$ is 19 for those with fewer than 12 years of education, and 111 for those with more than 12 years.

\section{DISCUSSION}

The results show that low educational level predicts 10 year CHD mortality independently of traditional risk factors. Notably, the risk associated with low education is comparable in magnitude to many of the traditional risk factors, including cholesterol level, smoking status, sex, and age, that are used in current treatment guidelines. These findings suggest the possibility that an educational level of less than 12 years may be used to identify persons at higher absolute risk of death from CHD who would not otherwise be identified for treatment.

The incorporation of low education into treatment guidelines could potentially reduce socioeconomic disparities in CHD mortality. Although education cannot be modified medically, it can be used, as are other nonmodifiable sociodemographic risk factors such as age and sex, to select persons for more intensive management of modifiable risk factors. Subgroup analyses of clinical trials suggest that persons of lower socioeconomic status derive as much, if not more, benefit from CHD interventions than persons of higher socioeconomic status. ${ }^{21}$ 


\begin{tabular}{|c|c|c|c|c|}
\hline \multirow[b]{2}{*}{$\begin{array}{l}\text { Cholesterol } \\
\text { Level (mg/dL) }\end{array}$} & \multicolumn{2}{|c|}{$\begin{array}{l}<12 \text { Years } \\
\text { Education }\end{array}$} & \multicolumn{2}{|c|}{$\begin{array}{l}\geq 12 \text { Years } \\
\text { Education }\end{array}$} \\
\hline & $\begin{array}{c}\text { Mortality } \\
\text { Risk (\%) }\end{array}$ & $95 \% \mathrm{Cl}$ & $\begin{array}{l}\text { Mortality } \\
\text { Risk (\%) }\end{array}$ & $95 \% \mathrm{Cl}$ \\
\hline$\geq 280$ & 7.6 & $4.5-10.7$ & 2.2 & $0.6-3.8$ \\
\hline $240-279$ & 6.5 & $4.7-8.2$ & 1.4 & $0.7-2.0$ \\
\hline $200-239$ & 5.7 & $3.6-7.8$ & 1.6 & $0.8-2.3$ \\
\hline$<200$ & 2.4 & $0.6-3.8$ & 1.3 & $0.7-2.0$ \\
\hline
\end{tabular}

The clinical application of risk stratification based on lower socioeconomic status represents a novel strategy for addressing socioeconomic disparities in conditions other than $\mathrm{CHD}_{i}$ it applies to any condition where treatment decisions are based on risk and where socioeconomic status is a risk factor. Such a strategy suggests more resources be directed toward primary or secondary prevention for diseases that occur at higher rates or at earlier ages among persons of lower socioeconomic status.

Use of an educational cutoff represents a simple, clinically applicable decision rule. Questions about education are less sensitive than questions about family income and are more reliably reported. Education is also subject to less change with time than income, which is strongly linked to employment status. Nonetheless, we observed similar results in our study using household income (results not shown).

The potential limitations of this study merit discussion. First, baseline assessments on subjects in NHANES I were obtained more than 25 years ago. Potentially, the relation between socioeconomic status and CHD could have changed during this period. Available evidence suggests, however, that socioeconomic disparities in CHD mortality have increased, not decreased, with time. ${ }^{22-24}$ Second, low-density lipoprotein or high-density lipoprotein levels were not assessed. Given the modest and inconsistent relationship between years of education and these lipoprotein levels, ${ }^{25,26}$ appreciable confounding by these factors is unlikely. Third, previous studies have shown that socioeconomic status is also associated with nontraditional CHD risk factors not included in this analysis, such as fibrinogen ${ }_{1}^{27} \mathrm{C}$-reactive protein ${ }_{1}^{28}$ apolipoproteins, ${ }_{1}^{27}$ hostility ${ }_{1}^{29,30}$ psychological distress, ${ }^{31}$ social support ${ }^{32}$ passive smoking, ${ }^{33}$ and job control. ${ }^{34}$ These unmeasured factors could account for the effect of education on mortality. Even so, however, none of these factors is included in ATP III guidelines, so their relevance to the question of including education in these guidelines is moot.

Fourth, it is possible that our findings are attributable to greater modification in traditional risk factors among more educated persons after baseline assessment of these factors. For example, rates of smoking cessation are significantly higher among those with higher education ${ }^{35} ;$ higher rates of subsequent smoking cessation by more educated persons may contribute to their lower CHD death rate. Given the limitations of the data, we cannot exclude this possibility; yet, if the goal of risk-based decision models is to identify persons in need of more intensive treatment, the pathway or mechanism that produces this heightened risk is not pertinent. The relevant question is whether the addition of a particular risk factor to the model improves prediction of the outcome.

Last, showing that education independently predicts risk at all cholesterol levels in an observational study does not definitively establish using a lower treatment threshold for less-educated persons to improve outcomes. ${ }^{36}$ Our view is that if the model observed here is validated in other cohorts, then the potential benefits of including low education as a risk factor in reducing both total CHD mortality and disparities in mortality likely outweigh the risks.

In summary, low socioeconomic status as measured by fewer than 12 years of education is associated with a CHD mortality risk comparable to traditional CHD risk factors. Use of a low educational level to identify persons at higher risk, who are not otherwise identifiable under current guidelines, may facilitate progress toward the elimination of socioeconomic disparities in health.

To read or post commentaries in response to this article, see it online at http://www.annfammed.org/cgi/content/full/2/5/469.

Key words: Socioeconomic factors; coronary heart disease; risk assessment; socioeconomic status

Submitted June 2, 2003; submitted, revised, August 8, 2003; accepted August 29, 2003.

\section{References}

1. Sorlie PD, Backlund E, Keller JB. US mortality by economic, demographic, and social characteristics: the national longitudinal mortality study. Am J Public Health. 1995;85:949-956.

2. Lantz PM, House JS, Lepkowski JM, Williams DR, Mero RP, Chen J. Socioeconomic factors, health behaviors, and mortality: results from a nationally representative prospective study of US adults. JAMA. 1998;279:1703-1708.

3. Marmot MG, Shipley MJ, Rose G. Inequalities in death--specific explanations of a general pattern? Lancet. 1984;1:1003-1006.

4. Smith GD, Neaton JD, Wentworth D, Stamler R, Stamler J. Socioeconomic differentials in mortality risk among men screened for the Multiple Risk Factor Intervention Trial: I. White men. Am J Public Health. 1996;86:486-496. 
5. Pamuk E, Makuc D, Heck K, Reuben C, Lochner K. Socioeconomic Status and Health Chartbook. Health, United States, 1998. Hyattsville, Md: National Center for Health Statistics; 1998.

6. Bowlin SJ, Medalie JH, Flocke SA, Zyzanski SJ, Goldbourt U. Epidemiology of intermittent claudication in middle-aged men. Am J Epidemiol. 1994; 140:418-430.

7. Lapidus L, Bengtsson C. Socioeconomic factors and physical activity in relation to cardiovascular disease and death. A 12 year follow up of participants in a population study of women in Gothenburg, Sweden. Brit Heart J. 1986;55:295-301.

8. Vogels EA, Lagro-Janssen AL, van Weel C. Sex differences in cardiovascular disease: are women with low socioeconomic status at high risk? Br J Gen Pract. 1999;49:963-966.

9. Kaplan GA, Keil JE. Socioeconomic factors and cardiovascular disease: a review of the literature [Review]. Circulation. 1993;88:1973-1998.

10. Expert Panel on Detection EaToHB, Cholesterol iA. Executive Summary of The Third Report of The National Cholesterol Education Program (NCEP) Expert Panel on Detection, Evaluation, And Treatment of High Blood Cholesterol In Adults (Adult Treatment Panel III). [see comments]. JAMA. 2001;285:2486-2497.

11. Hardarson T, Gardarsdottir M, Gudmundsson KT, Thorgeirsson $\mathrm{G}$, Sigvaldason $\mathrm{H}$, Sigfusson N. The relationship between educational level and mortality. The Reykjavik Study. J Intern Med. 2001;249:495-502.

12. Pocock SJ, Shaper AG, Cook DG, Phillips AN, Walker M. Social class differences in ischaemic heart disease in British men. Lancet. $1987 ; 2: 197-201$.

13. Engel A, Murphy RS, Maurer K, Collins E. Plan and operation of the NHANES I Augmentation Survey of adults 25-74 years, United States, 1974-75. Vital and health statistics, series 1, no. 14. Washington, DC: US Government Printing Office; 1978. DHEW publication no. (PHS) 78-1314.

14. Miller HW. Plan and operation of the Health and Nutrition Examination Survey, United States, 1971-73. Vital and health statistics, series 1, no. 10a, 10b. Washington, DC: US Government Printing Office; 1977. DHEW publication no. (PHS) 73-1310.

15. Cohen BB, Barbano HE, Cox CE, et al. Plan and operation of the NHANES I Epidemiologic Followup Study, 1982-84. Vital and Health Statistics. Series 1, No. 22. Washington, DC: US Government Printing Office, 1987. DHHS Pub. No. (PHS) 87-1324.

16. Cox CS, Rothwell ST, Madans JH, et al. Plan and operation of the NHANES I Epidemiologic Followup Study. 1987. National Center for Health Statistics. Vital Health Stat 1. No.27; 1992.

17. Madans JH, Cox CS, Kleinman JC, et al. 10 years after NHANES I: mortality experience at initial followup, 1982-84. Public Health Rep. 1986; 101:474-481.

18. Research Triangle Institute. SUDAAN: Professional Software for Survey DAta ANalysis, Version 8.0. Research Triangle Park; 2001.

19. Zhang J, Yu KF. What's the relative risk? A method of correcting the odds ratio in cohort studies of common outcomes. JAMA. 1998;280:1690-1691.

20. Graubard BI, Korn EL. Predictive margins with survey data. Biometrics. 1999;55:652-659.
21. National Heart, Lung, and Blood Institute. What Have we Learned About Socioeconomic Status and Cardiovascular Disease from Large Clinical Trials. Bethesda, Md: National Heart, Lung, and Blood Institute, National Institute of Health; 1995.

22. Schalick LM, Hadden WC, Pamuk E, Navarro V, Pappas G. The widening gap in death rates among income groups in the United States from 1967 to 1986. Int J Health Serv. 2000;30:13-26.

23. Crimmins EM, Saito Y. Trends in healthy life expectancy in the Unit ed States, 1970-1990: gender, racial, and educational differences. Soc Sci Med. 2001;52:1629-1641.

24. Cooper R, Cutler J, Desvigne-Nickens P, et al. Trends and disparities in coronary heart disease, stroke, and other cardiovascular diseases in the United States: findings of the national conference on cardiovascular disease prevention. Circulation. 2000;19:3137-3147.

25. Winkleby MA, Robinson TN, Sundquist J, Kraemer HC. Ethnic variation in cardiovascular disease risk factors among children and young adults: findings from the Third National Health and Nutrition Examination Survey, 1988-1994. JAMA. 1999;281:1006-1013.

26. Freedman DS, Strogatz DS, Williamson DF, Aubert RE. Education, race, and high-density lipoprotein cholesterol among US adults. Am J Publ Health. 1992;82:999-1006

27. Brunner EJ, Marmot MG, White IR, et al. Gender and employment grade differences in blood cholesterol, apolipoproteins and haemostatic factors in the Whitehall II study. Atherosclerosis. 1993;102:195-207.

28. Danesh J, Collins R, Appleby P, Peto R. Association of fibrinogen, C-reactive protein, albumin, or leukocyte count with coronary heart disease: meta-analyses of prospective studies. JAMA. 1998;279:1477-1482.

29. Carroll D, Davey SG, Sheffield D, Shipley MJ, Marmot MG. The relationship between socioeconomic status, hostility, and blood pressure reactions to mental stress in men: data from the Whitehall II study. Health Psychol. 1997;16:131-136.

30. Scherwitz L, Perkins L, Chesney M, Hughes G. Cook-Medley Hostility scale and subsets: relationship to demographic and psychosocial characteristics in young adults in the CARDIA study. Pschosomat Med. $1991 ; 53: 36-49$

31. Fiscella K, Franks P. Does psychological distress contribute to racial and socioeconomic disparities in mortality? Soc Sci Med. 1997;45:1805-1809.

32. Orth-Gomer K, Rosengren A, Wilhelmsen L. Lack of social support and incidence of coronary heart disease in middle-aged Swedish men. Pschosomat Med. 1993;55:37-43.

33. Kritz $H$, Schmid $P$, Sinzinger $H$. Passive smoking and cardiovascular risk. Arch Intern Med. 1995:155:1942-1948.

34. Marmot MG, Bosma H, Hemingway H, Brunner E, Stansfeld S. Contribution of job control and other risk factors to social variations in coronary heart disease incidence. Lancet. 1997;350:235-239.

35. Centers for Disease Control and Prevention. Smoking cessation during the previous year among adults-United States, 1990-1991. MMWR. 1993:42:504-507.

36. Ridker PM, Rifai N, Clearfield M, et al. Measurement of C-reactive protein for the targeting of statin therapy in the primary prevention of acute coronary events. N Engl J Med. 2001;344:1959-1965. 